\title{
S. Linguagens \\ O PARÂMETRO DO SUJEITO NULO: UMA ANÁLISE CONTRASTIVA ENTRE O PORTUGUÊS E O ALEMÃO
}

\author{
Carla Carine Gerhardt (UFSM)
}

\begin{abstract}
RESUMO: o objetivo deste trabalho é apresentar, através dos pressupostos da Gramática Universal (GU), que faz parte da Gramática Gerativa, desenvolvida por Noam Chomsky (1965), como a questão do parâmetro do sujeito nulo se sucede em línguas que não seguem todos os princípios da GU, como o português. Para realizar tal apresentação, são apresentados os principais teóricos do inatismo, como teoria de aquisição e desenvolvimento da linguagem, e os pressupostos da GU, conforme sua constituição histórica. Depois, comparam-se exemplares de frases da língua portuguesa, em que o parâmetro do sujeito nulo ocorre, com exemplares correlatos de frases da língua alemã, em que a expressão do sujeito é obrigatória e constitui um princípio. Assim, é utilizada uma oração com sujeito oculto e outra sem sujeito, da língua portuguesa. Através dessa análise, evidencia-se que a gramática universal, apesar de possuir princípios rígidos, pode comportar os chamados parâmetros, que são princípios abertos, obtidos através do meio linguístico ambiente.
\end{abstract}

PALAVRAS-CHAVE: Teorias de aquisição da linguagem. Gramática Gerativa. Parâmetro do sujeito nulo.

\begin{abstract}
Universal Grammar (UG), developed by Noam Chomsky (1965), how the null subject parameter occurs in languages that do not follow all the principles of UG, such as Portuguese. To do this, we present both the central tenets of UG and innatism - one of the leading theories of language acquisition and development, according to its historical development. Then, sentence examples from the Portuguese language, in which the null subject parameter occurs, are compared with cases from German, in which the subject is obligatory and constitutes a principle. Thus, a clause with a hidden subject (German) and another with no subject (Portuguese) are used. This analysis made evident that, despite having rigid principles, universal grammar can include the so-called parameters, which are open principles, obtained from the linguistic environment.
\end{abstract}

KEYWORDS: Theories of language acquisition. Grammar. Null subject parameter.

\section{INTRODUÇÃO}

Ao longo dos últimos anos, por todo o mundo, muito é pesquisado e estudado pelos linguistas e psicólogos sobre como uma língua é apreendida por uma criança. Eis que surgem as chamadas teorias de aquisição da linguagem. A primeira delas começou a ser desenvolvida pelo estadunidense Pavlov, em 1913, e teve seu auge com Skynner. Para eles, o processo de aprendizagem ocorre a partir de associações entre estímulos e respostas e de repetições de comportamentos bem-sucedidos. O processo de aprendizagem é, portanto, produto da interação do organismo com o seu meio. “A partir da imitação de sons e padrões, da prática assistida com reforços negativos e positivos e 


\section{Linguagens}

da formação de hábitos, a criança constituirá a sua língua". (FINGER; QUADROS, 2007, p. 21). Trata-se de uma teoria comportamental de aquisição.

Essa perspectiva comportamental perdurou com força até os anos 50, quando estudos complementares começaram a surgir. A partir de Noam Chomsky (1965), a linguagem não foi mais vista como resultado de convenções, mas como herança genética, inata ao ser humano. O linguista sustenta sua hipótese ao afirmar que crianças podem pronunciar sentenças que nunca ouviram antes:

\footnotetext{
segundo Chomsky, a tese de que a linguagem é um comportamento aprendido tinha um "furo" bem óbvio: todos nós sabemos falar frases que nunca ouvimos antes, e somos até mesmo capazes de inventar palavras. Uma criança de quatro anos já consegue produzir milhares de enunciados diferentes - é difícil acreditar que ela tenha ouvido dos pais ou outras pessoas, não é?. (GUIMARÃES, 2014, p. 16).
}

Assim, "a corrente inatista defende que as crianças possuem suas próprias regras de fala e que estas vão sendo aprimoradas por meio da convivência com os adultos". (SILVA, 2008, p. 2).

Mais tarde, surgiram teorias cognitivas, como o construtivismo de Piaget e o interacionismo de Vygotsky. Estes teóricos passam a pensar não só nas formas de aquisição da linguagem, mas na relação linguagem/ pensamento. Essas abordagens, então, buscam dar conta da linguagem a partir das relações interativas entre a criança e o ambiente, sendo a linguagem consequência da construção da linguagem em geral (hipótese construtivista de Piaget) ou entre a criança e as pessoas com quem ela convive (hipótese interacionista de Vygotsky).

Neste trabalho, apenas a teoria inatista de aquisição da linguagem é tomada como foco de análise. São apresentados exemplos desta teoria a fim de verificar como ela ocorre na prática. Alguns trabalhos já foram publicados a esse respeito. Guimarães (2014) aponta um exemplo de comunidade linguística indígena, que poderia comprovar as ideias chomskyanas, pelo fato de os índios praticamente não conviverem com outras fontes de comunicação a não ser a própria. No entanto, a análise das frases proferidas por essas pessoas mostra que seu potencial linguístico é extremamente reduzido. Trata-se de uma 


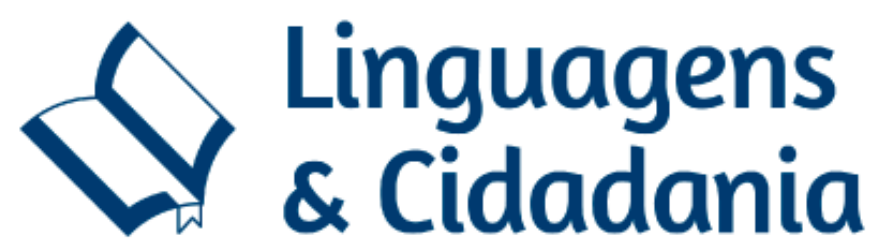

tribo de cerca de 300 índios, os pirahãs, que vivem no Amazonas, próximo à divisa com Rondônia:

De acordo com o americano Dan Everett, que viveu com eles durante sete anos, a língua dos pirahãs não tem palavras para expressar os números além do três, não tem tempos verbais e não permite a recursividade, ou seja, a possibilidade de construir enunciados encaixando uma frase na outra. Assim, eles seriam capazes de dizer "a canoa de João" e "o irmão de João", mas não "a canoa do irmão de João". Se colocado em confronto direto com a teoria de Chomsky, o caso dos pirahãs só poderia significar duas coisas: ou os pirahãs não são humanos - o que, obviamente, é absurdo -, ou a tese chomskyana dos princípios universais da linguagem estaria "furada". Dan Everett causou rebuliço no meio linguístico quando publicou suas descobertas [...]. (GUIMARÃES, 2014, p. 18).

Assim, a teoria inatista de que o ser humano consegue, sem influências externas, produzir infinitos números de sentenças, é desmistificada.

O presente trabalho busca apresentar uma análise contrastiva entre o português e o alemão em relação ao parâmetro do sujeito nulo, princípio teórico da gramática gerativa que diz que algumas línguas fogem ao princípio da expressão obrigatória do sujeito em frases. Nesse sentido, Marins (2009) aponta um estudo contrastivo, sobre o mesmo tema, entre o português e o italiano:

\footnotetext{
Segundo a hipótese de que línguas que apresentam um paradigma flexional verbal funcionalmente rico licenciam o apagamento do sujeito (Roberts, 1993), esperava-se que o italiano exibisse propriedades prototípicas de línguas de sujeito nulo, exatamente como afirmam os estudos teóricos gerativistas. Os resultados mostram que há, no italiano, uma preferência pelo apagamento do sujeito em todos os contextos em que o português brasileiro (PB) tende a realizar foneticamente a posição. (MARINS, 2009, res.).
}

Percebe-se que a pesquisadora apresentava a hipótese de que o parâmetro do sujeito nulo ocorria da mesma forma em línguas cuja incidência do parâmetro era apontada. No entanto, ela verificou que, em cada língua, ele ocorre de forma aleatória, com diferentes números de casos.

Neste trabalho, será feita uma análise comparativa entre a língua portuguesa e língua alemã, em que, a princípio, naquela, há o parâmetro do sujeito nulo e, nesta, o princípio da expressão do sujeito. A escolha da língua portuguesa ocorreu por ser a língua materna da autora, cujos conhecimentos a respeito do funcionamento da língua podem 


\section{Linguagens}

ser considerados o suficiente para análises linguísticas, também por ela ser graduada em Língua Portuguesa. Já a escolha pelo alemão deu-se devido à empatia da autora com a língua, que nasceu e cresceu em meio a uma colônia de alemães no Brasil e, por isso, considera o alemão a sua segunda língua.

A seguir, são apresentados os pressupostos teóricos que envolvem o desenvolvimento do presente trabalho.

\section{PRESSUPOSTOS TEÓRICOS}

Para facilitar a compreensão do ponto chave deste trabalho, a questão do parâmetro do sujeito nulo, comparado nas línguas alemã e portuguesa, é preciso que se faça um apanhado histórico/conceitual dos princípios básicos e dos divulgadores da Gramática Gerativa, desenvolvida fundamentalmente por Chomsky (1965), e amplamente divulgada em vários países e línguas. Depois disso, é abordada uma ramificação dessa gramática, a noção de parâmetro do sujeito nulo, sobre a qual são lançados exemplos descritivos.

\section{1 A GRAMÁTICA UNIVERSAL}

Primeiramente, destaca-se propriamente Noam Chomsky, nascido em Filadélfia, 1928, foi um grande cientista, filósofo e pesquisador da cognição. Estudou Filosofia e Linguística na Universidade da Pensilvânia, realizando também, trabalho de pesquisador assistente na Universidade de Harvard. Atualmente, é professor emérito em Linguística no Instituto de Tecnologia de Massachusetts e nomeado na Cátedra de Línguas Modernas e Linguística Ferrari P. Ward. Como fruto de sua tese de $\mathrm{PhD}$, surgiram as originais abordagens de seus ideais linguísticos inatistas, que fugiam do anterior ideal comportamental behaviorista:

A teoria inatista da aquisição da linguagem tem como principal representante o linguista Noam Chomsky, que adotou uma postura contrária ao behaviorismo de Skinner vigente na época, onde argumenta que a linguagem é uma herança genética e não um conjunto de comportamentos verbais como afirma o behaviorismo. O organismo básico de Chomsky é: num tempo 


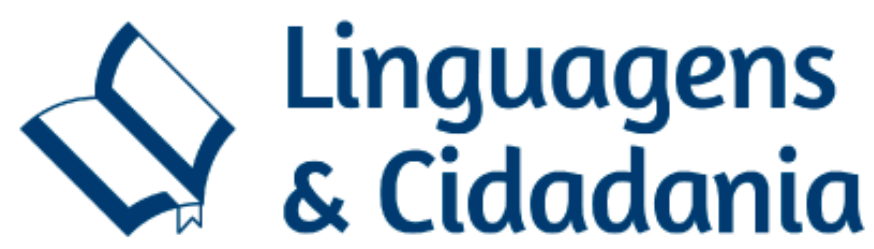

bastante curto (mais ou menos dos 18 aos 24 meses), a criança, que é exposta normalmente a uma fala precária, fragmentada, cheia de frases truncadas ou incompletas, é capaz de dominar um conjunto complexo de regras ou princípios básicos que constituem a gramática internalizada do falante. (SOUZA, 2012, p. 1).

Em Portugal, a função de divulgação da Gramática Universal é assumida por Eduardo Paiva Raposo, linguista e pesquisador da área. Nascido em Lisboa, 1949, foi um dos membros fundadores do GELT (Grupo de Estudos de Linguística Teórica), que introduziu e divulgou a teoria da gramática gerativa em Portugal. Em 1973, entrou como Assistente na Faculdade de Letras de Lisboa, depois de, neste local, ter completado a licenciatura em Filologia Românica. Estudou, igualmente, na Universidade da Califórnia em San Diego e no MIT. Em 1982, doutorou-se em Linguística Portuguesa pela Universidade de Lisboa, onde passou a lecionar como Professor Auxiliar. É autor do livro Introdução à Gramática Gerativa e de vários artigos sobre sintaxe do Português em revistas da especialidade, como Linguistic Inquiry e Natural Language and Linguistic Theory. Sua área de trabalho é Linguística, com especializações em linguística teórica, sintaxe e semântica, gramática gerativa, Português e Romance, da mesma forma que morfossintaxe.

Raposo (1992), descreve, com base na Gramática Gerativa, segundo os pressupostos de Chomsky (1965), que existe um sistema chamado faculdade da linguagem em todas as pessoas. Essa faculdade é inata aos seres humanos, ou seja, todos nascem dotados dela. O sistema linguístico encontrado nessa faculdade é chamado gramática. Ao estado inicial desse sistema no bebê, dá-se o nome de Gramática Universal.

Raposo (1992, p. 49-50) explica:

\footnotetext{
a teoria da Gramática Universal desta fase da gramática generativa é conhecida sob o nome de Teoria Standard e recebe a sua formulação mais explícita e desenvolvida em Chomsky (1965). A Teoria Standard é uma teoria de regras gramaticais, na medida em que concebe as gramáticas essencialmente como sistema de regras, funcionando de uma certa maneira e mantendo entre si um número restrito de interacções possíveis. [...]
}

Esse modelo descritivo da língua permitiu o desenvolvimento de diversas gramáticas. Como a Gramática Universal (UG - Universal Grammar) deve ser uma só, segundo se induz pelo próprio nome, a Teoria apropriou-se de uma "medida de 


\section{W. Linguagens}

avaliação", que classificava as gramáticas. Aquela que fosse mais curta, ou seja, utilizasse o menor número de símbolos para descrever o maior número de casos, ficaria com a maior classificação e era mantida como a UG. Porém, por volta dos anos 60, devido à enorme variedade de gramáticas desenvolvidas, que possuíam alto poder expressivo e explicativo, o que era contrário ao modelo descritivo da UG, linguistas desenvolveram um modelo alternativo para ela, a Teoria Standard Alargada.

A partir dessa não nova, mas reformulada teoria, reduziu-se a enorme variedade de sistemas de regras, as quais passaram a atuar em conjunto com princípios restritivos universais, que caracterizam possíveis gramáticas, como afirma Raposo (1992, p. 53):

\footnotetext{
$\mathrm{O}$ modelo que emerge progressivamente de todo este trabalho (chamado Teoria Standard Alargada) pode ser caracterizado como um modelo de regras e princípios (por oposição ao modelo Standard, um modelo unicamente de regras). Segundo a concepção da Teoria Standard Alargada, a gramática contém um número distinto e autônomo de componentes, cada uma delas com uma organização própria, caracterizada por um pequeno número de regras e por princípios que restringem a aplicação dessas regras.
}

Mais adiante, proposto por Chomsky (1965), surge o modelo de Princípios e Parâmetros, que incorpora grande parte dos resultados teóricos da Teoria Standard Alargada. Porém, com o passar do tempo, ele abandona totalmente as regras para permanecer apenas com o modelo de Princípios, na qual "cada um dos componentes da gramática é extremamente simples na sua organização interna, e mantém uma rede de interações com os outros componentes”. (RAPOSO, 1992, p. 54).

Nessa nova concepção, a UG é constituída por dois sistemas de princípios: aquele em que os Princípios são rígidos, invariáveis, e que qualquer gramática final terá de incorporar; e aquele em que os princípios são abertos, os Parâmetros. Estes últimos são "uma espécie de comutadores linguísticos, cujo valor final e definitivo apenas é atingido durante o processo de aquisição, através da sua fixação numa de duas posições possíveis com base na informação obtida a partir do meio linguístico ambiente”. (RAPOSO, 1992, p. 54-55). Nesse sentido, afirma Kato (2002, p. 311): 


\section{W. Linguagens}

invariantes e propriedades paramétricas, estas com seus valores definidos a partir da língua que lhe serviu de "input" no período da aquisição.

Mais tarde, Chomsky desenvolve uma nova concepção teórica e metodológica de sua perspectiva (LOPES, 2001), o Programa Minimalista (PM). Neste, são usados os termos princípio ótimo e princípio econômico para tratar da estrutura da GU. Conforme Lopes (2001, p. 3),

Chomsky (1998) aponta duas versões para a tese minimalista: a fraca e a forte. A versão fraca baseia-se em Occam's razor e é o que Uriagereka (1999) chama de minimalismo "metodológico", pois busca a forma mais otimizada de teorizar; em poucas palavras, quanto menos, melhor: um axioma é melhor que dois, um algoritmo é melhor que dois etc. A versão forte, batizada por ele de minimalismo "ontológico", não considera quão ótima é a teoria sobre a Faculdade da Linguagem, mas quão ótima é a Faculdade da Linguagem propriamente.

Assim, independente do modelo de cada época, sempre há uma língua perfeita, e qualquer desvio provém apenas de fatores externos: uma gramática descritivamente adequada é aquela em que "se descreve corretamente a competência intrínseca do sujeito indígena ideal”. (CHOMSKY, 1965, p. 42 [24]). Em síntese, a teoria chomskyana pode ser vista sob três aspectos:

A teoria de Noam Chomsky é chamada de [1] gerativismo porque, segundo ela, a partir de um número finito de regras gramaticais, o ser humano consegue gerar um número infinito de enunciados. Também é chamada de [2] inatismo por defender que, assim como um joão-de-barro já nasce sabendo construir casinhas de barro ou uma abelha já nasce sabendo produzir mel, o ser humano já nasce sabendo formar palavras e frases por meio da gramática universal embutida em seu cérebro. E, finalmente, também é chamada de [3] mentalismo por se interessar mais pelos aspectos mentais do que pelos aspectos materiais das línguas. Chomsky acha que os linguistas devem estudar os universais linguísticos - aqueles princípios universais aplicáveis a qualquer língua porque isso permitirá, em um segundo momento, entender como o ser humano constrói seu conhecimento de maneira mais ampla. (GUIMARÃES, 2014, p. 17).

Quanto ao objeto desta teoria, segundo Dias e Gomes (2008), Chomsky delimita seu objeto de estudo - a competência - e deixa de lado o desempenho (Figura 1), e, por isso, pode ser comparado a Saussure, que também estabeleceu um objeto - a língua -, e descartou a fala. O estruturalista Chomsky, ainda "dentro da competência, define a 


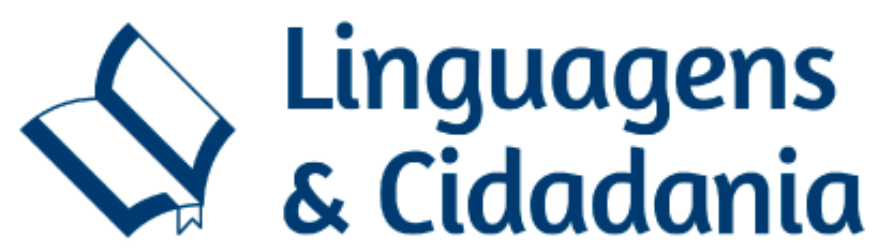

sintaxe como nuclear, considerando a fonologia e a semântica como periféricas. $\mathrm{Na}$ sintaxe, deixa de lado as particularidades das línguas e estuda os universais linguísticos" (DIAS; GOMES, 2008, p. 44), e, por fim, a partir dos universais, delimita-se nos princípios e abandona os parâmetros.

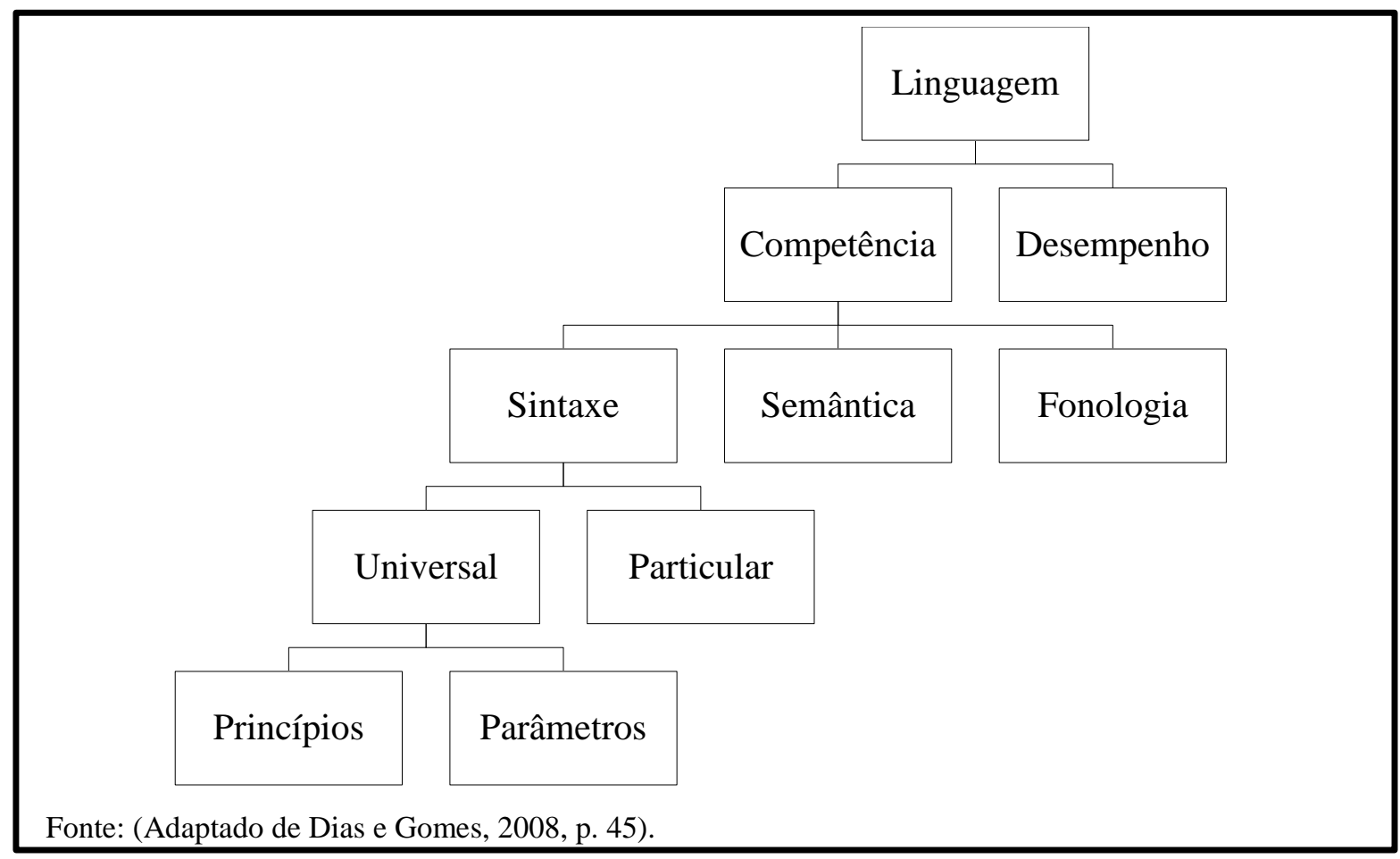

Figura 1 - Delimitações de Chomsky nos estudos inatistas.

De acordo com o modelo de princípios e parâmetros, a ligação destes é determinada por dados linguísticos, que permitem à criança decidir qual posição atribuir a cada um. Esse processo pode ocorrer no ponto principal de análise desse trabalho: o parâmetro do sujeito nulo, ou pro-drop.

\subsection{O PARÂMETRO DO SUJEITO NULO}

A Gramática Universal (UG) possui um princípio universal rígido, que diz respeito ao fato de que todas as línguas existentes no mundo devem ter um sujeito expresso fonologicamente em suas orações. Fonologicamente expresso, aqui, quer dizer que é necessária a pronúncia ou a sinalização de um sujeito na oração, seja ele um 


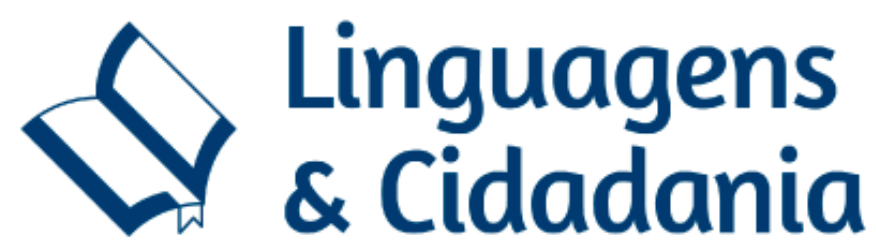

substantivo ou um pronome substantivo. Línguas como o alemão, o inglês e o francês estão subordinadas a esse princípio. Algumas outras línguas, porém, como o português, o italiano e o espanhol, subordinam-se ao parâmetro do sujeito nulo. Ou seja, nestas línguas é possível deixar a posição de sujeito vazia.

Assim, segundo os estudos apontados pela UG, que trabalha com os princípios da faculdade da linguagem, a qual abrange todo um conjunto de propriedades inatas, biologicamente determinadas, cujo desenvolvimento ocorre na interação do sujeito com o meio ambiente, determinando a gramática particular de cada indivíduo, fica disposto que a criança, ao desenvolver sua linguagem, de acordo com o parâmetro do sujeito nulo, deve realizar uma escolha. Essa escolha se dá entre a fixação da realização fonética obrigatória, que ocorre em línguas como o alemão, o inglês e o francês, e a realização fonética opcional do sujeito, que ocorre em línguas românicas como o português, o italiano e o espanhol.

Dessa forma, a criança terá um parâmetro com duas posições possíveis. A opção dependerá dos dados linguísticos recebidos primariamente por ela, ou seja, uma criança que cresça numa comunidade em que se fala português, não terá dificuldade em fixar o parâmetro que possui a forma de expressão opcional do sujeito, pois irá ouvir sempre expressões com esse tipo de caracterização. O mesmo irá acontecer com aquela criança que, por ventura, crescer em meio à língua alemã, na qual ela irá agregar com a mesma facilidade o parâmetro da realização fonética obrigatória do sujeito.

\section{METODOLOGIA}

Para a constituição do corpus de análise, foram selecionadas frases aleatórias da língua portuguesa, uma em que o sujeito não aparecia fonologicamente expresso (sujeito oculto), e outra em que seu uso não se faz necessário (oração sem sujeito): "temos uma maçã" e "está chovendo". A partir delas, foram feitas correlações de sentido e estrutura com as frases correspondentes em alemão. Assim, foi possível verificar como se constitui a noção de princípios e parâmetros, por meio de análise linguística comparativa.

\section{RESULTADOS}


O português pode ter o que chamamos de sujeito oculto, como na oração (4) do Quadro 1, ou até mesmo o que chamamos de oração sem sujeito, como na oração (10) do mesmo quadro. O símbolo $\varnothing$, usado na tabela, significa que o sujeito está elíptico e não se encontra fonologicamente expresso na oração.

Quadro 1 - Diferenças oracionais entre o alemão e o português quanto ao parâmetro do sujeito nulo

\begin{tabular}{l|l} 
Alemão & Português \\
\hline (1) Wir haben einen Apfel. & (2) Nós temos uma maçã. \\
\hline (3) Wir haben einen Apfel. & (4) Ø Temos uma maçã. \\
\hline (5) Einen Apfel haben. & (6) Ter uma maçã. \\
\hline (7) Es ist regnerisch. & (8) Isto está chovendo. \\
\hline
\end{tabular}

“Wir”, do alemão, significa "nós”, ou seja, é um pronome pessoal de $1^{\mathrm{a}}$ pessoa do plural. Na primeira oração do quadro, "wir haben einen Apfel", "wir" ocupa a posição de sujeito. A oração, dessa forma, pode ser traduzida como "nós temos uma maçã". No português, podemos omitir esse sujeito: “temos uma maçã". No alemão, porém, isso não pode ser realizado. O sujeito deve, obrigatoriamente, ser expresso na oração, caso contrário, seu sentido muda: "Einen Apfel haben", sem a presença do pronome "wir", significa "ter uma maçã", pois o verbo "haben" (ter) está no infinitivo, ficando sua tradução também nessa forma. Em uma frase com o uso sujeito, poderíamos ter a instanciação desse trecho da seguinte maneira: "Ich möchte einen Apfel haben", que significa "eu gostaria de ter uma maçã, cujo sujeito é “ich" (eu).

Nas orações 7 e 8 ocorre o mesmo, só que com um verbo impessoal: chover. "Es", do alemão, significa isto, ou seja, é um pronome pessoal neutro, que toma a função de sujeito na frase. A oração fica traduzida, literalmente, para o português, como "isto está chovendo". Na língua portuguesa esse pronome não se faz necessário, pois o verbo chover, justamente por ser impessoal, não admite um sujeito. A tradução correta seria, então, simplesmente, "está chovendo".

\section{CONSIDERAÇÕES FINAIS}

Linguagens \& Cidadania, v. 20, jan./dez. 2018. 
Portanto, é possível concluir que o parâmetro do sujeito nulo realmente ocorre em algumas línguas, como, no caso, o alemão. Dessa forma, foi possível verificar, também, que na Gramática Universal não existem só parâmetros inatos, rígidos, que condizem com a teoria da faculdade da linguagem. Existem também princípios abertos, os chamados parâmetros, que se desenvolvem com o passar do tempo, e através do meio linguístico no qual o indivíduo se encontra.

\section{REFERÊNCIAS BIBLIOGRÁFICAS}

CHOMSKY, N. Aspects of the Theory of Syntax. Cambridge, MA: MIT Press, 1965.

DIAS, L. S.; GOMES, M. L. C. Estudos linguísticos: dos problemas estruturais aos novos campos de pesquisa. Curitiba: Ibpex, 2008.

FINGER, I.; QUADROS, R. M. Teorias de aquisição da linguagem. Santa Catarina: Editora UFSC, 2013.

GUIMARÃES, T. Linguística 1. São Paulo: Pearson, 2014.

KATO, M. A. A evolução da noção de parâmetros. DELTA [online]. 2002, vol.18, n.2, pp. 309-337. ISSN 1678 460X. Disponível em:

<http://dx.doi.org/10.1590/S010244502002000200006>. Acesso em: 01 fev. 2015.

MARINS, J. E. O parâmetro do sujeito nulo: uma análise contrastiva entre o português e o italiano. 2009, 111 p. Dissertação (Mestrado em Letras Vernáculas) Universidade Federal do Rio de Janeiro, Rio de Janeiro, RJ, 2009.

LOPES, R. E. V. Aquisição da linguagem: novas perspectivas a partir do programa minimalista. In: DELTA: Documentação de Estudos em Lingüística Teórica e Aplicada, São Paulo, v. 17, n. 2., p. 245 - 241, 2001. Disponível em: http://www.scielo.br/scielo.php?pid=S0102-44502001000200004\&script=sci_arttext. Acesso em 20 jan. 2015.

RAPOSO, E. P. Teoria da Gramática: A faculdade da Linguagem. Lisboa: Caminho, 1992.

SILVA, B. Desenvolvimento da linguagem: uma proposta inatista. In: Jornada Nacional de Linguística e Filologia da Língua Portuguesa, 3, 5 nov. 2008, Rio de Janeiro, 2008. 


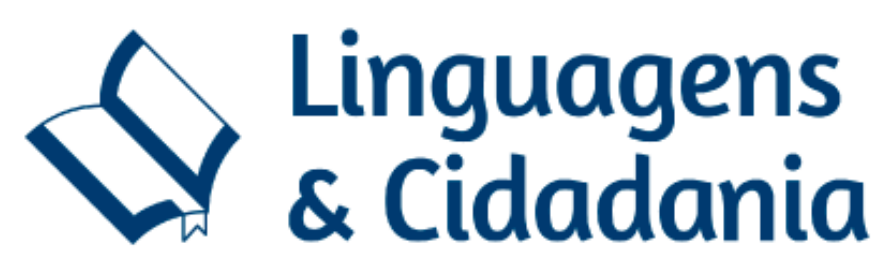

Trabalhos. Disponível em: 〈http://www.filologia.org.br/iiijnlflp/>. Acesso em: 19 fev. 2015.

SOUZA, A. R. B. et al. A teoria inatista de aquisição da linguagem. Revista Partes, p. 1 - 1, 2012. Disponível em: 〈http://www.partes.com.br/educacao/ateoriainatista.asp>. Acesso em: 02 fev. 2015. 